\title{
PEMIKIRAN FIQIH MODERAT DI TIMUR TENGAH DAN RELASINYA DENGAN GERAKAN FIQIH FORMALIS
}

\author{
M. Zaidi Abdadk
}

\begin{abstract}
A bstract: Islamicthought has conventionally distingiished between what it calls thePeople of Hadith (ahlu al-hadis) and thePeede of Opinion (ahl ar-ra'y). Thesetwo segments have improed intoa cauntless ament of thaught in themodem word, makingit impossibletorefer to a cetain type of thinking as this or that. Nonthdess, the basicharactes of themodem Musim thinking are not quite distindive from that of the dassical-dualistic didhotomy. Hence, thedash of discoursethat wewitnessed reently in various Mudimuorlds is reflective of theintdlectual tension between thePeople of Hadith and thePeepleof Opinion Thedash of discourse that we havejust refereel to even took theform of physical conflict surh as that which happenedinEgyptandAlgria. In thesetwoMusimcountriesthedash of discaursehas turmedinto thedash of politics, whererdigious radicalismand absodutismare the dominant features This paper seks to providea citique of this negative daddonent, offeing in the process a kind of discoursethat can serveas an altemative, namdy thediscourse of a modkate Islam
\end{abstract}

Keywords: ModkateIdam radicalism absodutism formalisticfigh

\section{Pendahuluan}

Sepanjang sejarah, perkembangan pemikiran keislaman telah menunjukkan adanya varian-varian. Varian itu berupa metodologi, kerangka berpikir, dan orientasi yang berbedabeda antara satu pemikiran dengan pemikiran yang lainnya. Fenomena seperti ini pada dasarnya sudah muncul sejak zaman Rasulullah Saw dan al-Khulafa'sal-Rashidun Pada masa itu sudah ada kecenderungan pemikiran yang jika dipetakan memunculkan madrasah hadith di satu sisi dan madrasah ráyi $d i$ sisi lain. ${ }^{1}$ Tetapi perbedaan yang tampak saat itu tidak begitu terlihat. Lain halnya pada masa D inasti Ummayah dan D inasti Abasiyah, madrasahhadithdan madrasah ráyi tampil begitu mencolok dalam panggung sejarah pemikiran dengan seperangkat metodologi dan landasan epistemologisnya.

Runtuhnya kekhalifahan Turki Uthmani yang diakibatkan oleh kolonialisme Barat, telah mempengaruhi perkembangan pemikiran keislaman hingga tampil lebih variatif. Kolonialisme telah cukup lama mengendalikan sendi-sendi kehidupan di negara-negara Islam, termasuk denyut kehidupan intelektualisme dunia Islam. Kolonialisme membuat kondisi umat Islam dilemahkan (mstadaf) di sektor pemikiran keislaman, sehingga yang muncul adalah kebekuan cara berpikir umat dan merajalelanya tradisi taqid karena pintu ijtihad dinyatakan tertutup. ${ }^{2}$ Kondisi ini yang mendorong lahirnya gerakan-gerakan pemikiran baru yang masing-masing menawarkan diri sebagai gerakan pemikiran alternatif.

*Fakultas Syari'ah IAIN Mataram NTB.

${ }^{1}$ Madrasahhdadthadalah semacam corak pemikiran keislaman yang mendasarkan pada nasżhir, sebaliknya madrasah ra'yiłebih banyak mendasarkan pada akal atau rasio dalam menggali pengetahuan keislaman. Lihat K huzaimah Tahido Yanggo, Pengantar Pedbandingan Mazhab(Jakarta: Logos, 1997).

${ }^{2}$ Lihat Ana Bilqis Fajar Wati "Pemikiran Keagamaan Fazlur Rahman (Studi atas Sumber-sumber Hukum Islam dan Terbukanya Pintu Ijtihad" dalam Antdog KajianIsam, Seri 10 (Surabaya: PPS IAIN Sunan Ampel Press, 2006), 51. 
Kebekuan pemikiran Islam jika dirunut jauh ke belakang sampai penggalan sejarah Islam zaman pertengahan, di mana pemikiran Islam kritis dan rasional - pasca Ibn Rushd ${ }^{3}$ terasa mati karena pintu ijtihad telah ditutup dan rasionalisme dikunci oleh arus deras pemikiran konservatif para ulama. Ketika itu, banyak pemikiran filsafat yang diharamkan atau bahkan sang pemikirnya dijatuhi hukuman mati dan fatwa kafir (takfir) karena dianggap filsafat adalah produk bidahyang datang bukan dari Islam. Banyak referensi mencatat bahwa hal demikian terjadi setelah al-Ghazali (1058-1111 M) menggugat dan mempertanyakan kaum filosof dalam bukunya, Tahafut al-Falasifah (Kerancuan atas Para Filosof). ${ }^{4}$ Ibn Sina (980-1037 M) dan al-Farabi (257 H/ 870 M), adalah dua filosof muslim yang menjadi obyek kritikan keras al-G hazali, dan dianggap banyak melakukan kesalahan dalam logika pemikiran metafisika (ketuhanan).

Gema tertutupnya pintu ijtihad tidak menghalangi gelombang kesadaran umat untuk mendobrak pintu itu dan memunculkan pemikiran-pemikiran alternatif berikutnya. Masih sejalur dengan tradisi pemikiran di era klasik, perkembangan pemikiran secara dikotomis menempati aras ahla al-hadith dan ahl ar-ra'y, walau dalam konteks kekinian dua poros pemikiran itu telah menurunkan beraneka macam varian baru. Pada dasarnya mereka ingin tampil sebagai gerakan pemikiran alternatif dalam menghadapi perkembangan dunia yang kian modern. Tak jarang yang muncul kemudian adalah perdebatan yang tidak sebatas perang wacana (dash of dscarse) tapi juga pergesekan dalam ranah politik (dash of politid. Sehingga fenomena saling hujat antar sesama pemikir muslim tidak bisa dihindari lagi.

Pada klimaksnya, masing-masing kubu yang bertikai itu tak jarang menggunakan caracara kekerasan (radikalisme) sebagai senjata untuk membungkam gerakan lawan. Sejarah telah mencatat itu, misalnya gerakan radikalisme di Mesir yang dilakukan oleh kaum fundamentalis di Al-Jazair dan demikian pula di Turki.

Tulisan ini adalah sebuah upaya untuk memetakan pemikiran Islam (fiqih) moderat yang berkembang di Timur Tengah, sekaligus menganalisis wacana yang diusung dalam rangka mengetengahkan potret intelektualisme Timur Tengah secara utuh dan obyektif. Peta sekaligus analisis wacana dalam dataran berikutnya dapat memberi inspirasi untuk melakukan kritik (naqd) dan sekaligus rekonstruksi (i'adah bumiyat minal-jadid) atas pemikiran yang sudah ada. D an di sinilah startingpain proyek pengembangan pemikiran Islam di masamasa mendatang.

\section{Batasan Istilah " Islam Moderat, Formalis, dan Timur Tengah"}

Dalam rangka memudahkan pemetaan, penulis perlu memberikan batasan terhadap istilah " Islam moderat", "formalis", dan "Timur Tengah". Tidak bisa ditampik bahwa keberadaan terminologi "moderat" dan "formalis" secara eksplisit diakui di negara-negara muslim, walaupun kedua terminologi tersebut, baik 'moderat' maupun 'formalis' masih dbbatabledi kalangan para pemikir dan pengkaji keislaman. Sekalipun demikian, perlu penulis paparkan dalam tulisan ini guna mengetahui ciri dan identitas kedua kelompok tersebut.

${ }^{3}$ Pemikiran Ibnu Rushd yang kritis dan rasional ini dapat dilihat pada Hasan Hanafi, Isamdog 2 dani Rasionalisme keEmpinsme(yogyakarta: LKiS, 2007), 145-241.

${ }^{4}$ Harun Nasution, Filsafat dan Mistiasme(Jakarta : Bulan Bintang, 1973), 34-36. 
Berdasarkan penelusuran penulis dari berbagai referensi, ${ }^{5}$ bahwa istilah Islam Moderat sebenarnya terbawa oleh konstalasi sosial politik. D engan demikian pembagian Islam menjadi moderat, liberal, fundamental, dan ekstrim itu juga tidak lepas dari penilaian yang berbedabeda. Sebenarnya kalau mau jujur, dalam Islam sendiri yang ada hanyalah Idam Rahłrah li al-Alamin ${ }^{6}$ Tetapi karena sudah terlanjur disebut menjadi istilah maka istilah moderat itu harus kita beri batasan. Sesungguhnya Moderat itu adalah keseimbangan antara keyakinan dan toleransi, seperti bagaimana kita mempunyai keyakinan tertentu tetapi tetap mempunyai toleransi yang seimbang terhadap keyakinan yang lain. Islam yang moderat itu adalah yang natural, ilmiah, dan siap untuk diaplikasikan dalam pergulatan hidup dan tentunya belum dimasuki interest-interest non agama?

Oleh banyak kalangan, Islam moderat lebih direpsentasikan kepada kelompok yang lebih modemis, progesif, dan reomis Pada awalnya Islam moderat ini sebenarnya adalah salafisme, yaitu keyakinan yang didirikan pada akhir abad ke-19 oleh para reformis muslim seperti Muhфmmad 'Abduh (w. 1323 H./ 1905 M.), Jamabal-D in al-Afghani>(w. 1314 H./ 1897 M.), Muhæmmad Rashid Ridф>(w. 1354 H./ 1935 M.), Muhæmmad al-Shawkani>(w. 1250 H./ 1834 M.), dan Jalałal-Shan'ani>(w. 1225 H./ 1810 M.). Namun, sejumlah orang menisbahkan asal-usul keyakinan Salafisme ini kepada Ibn Taimiyah (w. 728 H/ 1328 M.) dan muridnya yang bernama Ibn Q ayyim al-Jawziyah (w. 751 H./ 1350 H.). ${ }^{8}$

Istilah salaf berarti pendahulu, dan dalam konteks Islam, pendahulu itu merujuk pada preode Nabi, para sahabat, dan tabi'in. Selain itu, istilah salafi (seseorang yang mengikuti kaum salaf) punya makna fleksibel dan lentur serta memiliki daya tarik natural, sebab ia melambangkan autentisitas dan keabsahan. Para pendiri salafismemenegaskan bahwa dalam menghadapi semua persoalan, umat Islam seharusnya kembali kepada sumber tekstual asli yaitu al-Qur'an dan Sunnah Nabi. Dalam melakukannya, umat Islam harus menginterpretasikan sumber-sumber asli itu berdasarkan kebutuhan dan tuntutan modern tanpa harus terikat mutlak pada produk penafsiran generasi muslim awal. ${ }^{9}$ Seperti awalnya dipahami, salafisme tidak serta-merta anti intlektual, sebagaimana wahhabisme, tetapi ia cenderung tidak tertarik pada sejarah. D engan menekankan asumsi "zaman keemasan" di dalam Islam, para pengikut salafisme mengidealisasi zaman Nabi dan Sahabatnya, dan menolak atau tidak tertarik pada warisan sejarah Islam yang lebih besar.

Sementara "Islam formalis" adalah suatu istilah yang dilekatkan pada suatu kelompok Islam yang memiliki militansi dalam menyebarkan Islam. Oleh kebanyakan para pemikir, kelompok ini lebih direpsentasikan kepada suatu kelompok yang sangat fundametalis, militan,

${ }^{5}$ Lihat K holed Abou El-Fadl, SdamatkanISamdari MusimPuntan(Jakarta: Serambi Ilmu Semesta, 2006); Stephen Sulaiman Schwartz, DuaWajahIdamModeatismeus FundametalismedalamWacanaGldbal(Jakarta: Kerjasama Blantika dengan libforal-The Wahid Institut-Center for Islamic Pluralsm, 2007); Bahtiar Effendi, Idamdan Negara: Transformas Perikiran dan Praktdk Politik, (1998). Mochtar Pabotingi, "Tentang Visi, Tradisi, dan Hegomoni Bukan Muslim: Sebuah Analisis", dalam Mochtar Pabottingi (Ed)., Antara V is, Tradis, dan Heganoni Bukan Musim, (Jakarta: Yayasan O bor Indonesia, 1982).

${ }^{6}$ Lihat al-Q ur'an Surat al-Anbiya' (21): 107. Allah dengan tegas menyatakan: DantidaklahKami mengutuskamı (Muhammad) miainkan untuk mejadi rahprat bag semeta alam

7http:/ / tabloiddiplomasi.com/ index.php/ previous-isuue/ 52-maret-2008/ 474-islam-moderat-dalam-petadiplomasi-global, Edisi: Maret 2008.

${ }^{8}$ Abou El-Fadl, SAamatkanIdam 93.

${ }^{9}$ Ibid., 94. 
dxstrimis, radikal, jahidis, atau cukup dengan menamai istilah isamis Kholed Abou El-Fadl menyebut kelompok ini dengan istilah Puritan" ${ }^{10}$. D ia lebih suka mengambil istilah ini karena menurutnya ciri yang menonjol pada kelompok ini adalah menganut paham absdutismedan tak kenal kompromi dalam berkeyakinan. ${ }^{11}$ D alam berpikir, kelompok ini secara konsisten dan sistematis menganut absolutisme, berpikir dikotomis, dan bahkan idealistik. Pada isu tertentu, seperti bagaimana mereka menafsirkan warisan Nabi dan para Sahabat, kelompok ini cenderung menganut absolutisme dan kaku. Inilah yang dimaksud kelompok "Islam Formaslis" (Puritan) dalam tulisan ini.

Kelompok ini berawal dari Muhammad b. Abd al-Wahhab (w. 1206 H/ 1792 M) yang memiliki gagasan utamanya bahwa umat Islam harus dikembalikan kepada jalan yang benar agar mendapatkan rid Allah, karena ia memandang umat Islam telah melakukan kesalahan dan meyimpang dari jalan Islam yang lurus. D engan semangat puritan, Abd al-Wahhab hendak membebaskan Islam dari semua perusakan yang diyakininya telah menggerogoti agama Islam, yang di antaranya adalah tasawuf, doktrin perantara (tavassal), rasionalisme, ajaran Shişh, serta banyak praktik lain yang dinilainya sebagai inovasi bidah ${ }^{12}$

Kelompok ini cenderung menyikapi segala sesuatu yang tidak datang dari wilayah Arab sebagai sesuatu yang layak dicurigai, dan mereka percaya bahwa pengaruh dari non Islam itu berasal dari bangsa seperti Persia, Turki, dan Yunani. Misalnya, kaum Wahhabi percaya bahwa sufisme adalah sesuatu yang diimpor dari Persia. Kepercayaan yang menggunakan perantara (tamassil) para wali dan memuja makam suci berasal dari Turki. Sementara itu, rasionalismedan filsafat adalah pengaruh bangsa Yunani. ${ }^{13}$ Klaim Wahhabi ini terlalu menyederhanakan dan tidak akurat. Namun yang jelas, tidak perlu diragukan lagi bahwa kaum Wahhabi selalu menyamakan praktik budaya kehidupan Badui yang keras dengan satu-satunya Islam yang benar. ${ }^{14}$

Dengan melihat gambaran di atas, dapat dipetakan bahwa batasan pada kedua kelompok tersebut adalah terletak pada bagaimana mereka menyikapi teks keagamaan yang asli, yaitu al-Q ur'an dan Sunnah sebagai dasar kehidupan umat dan merespon kondisi yang berkembang selanjutnya. Islam Moderat adalah Islam yang lebih terbuka dalam melihat segala persoalan dan lebih fleksibel dalam mengambil keputusan melalui teks tersebut. Islam moderat lebih dapat menerima penafsiran sesuai dengan tuntutan zaman dan modernitas,

\footnotetext{
${ }^{10}$ Istilah "puritan" menurut K holed adalah yang paling tepat dipakai dalam konteks suatu kelompok Islam, mengingat akan lebih bisa dipahami menggambarkan pandangan yang bercorak reduksionisme fanatik dan literalisme cupat-pikir pada suatu kelompok. Sementara istilah fundamentalismenurutnya sangat tidak pas untuk konteks Islam, karena dalam bahasa Arab istilah itu dikenal dengan kata usclik,yang berarti "seseorang yang bersandar pada hal- hal yang bersifat pokok dan mendasar". Jadi fundamentalismeIdammemunculkan mispersepsi yang tidak bisa dihindari, bahwa hanya kelompok fundamentalis saja yang mendasarkan penafsiran mereka pada al-Qur'an dan Sunnah Nabi-sumber dasar dan fundamental bagi teologi dan hukum Islam. Padahal banyak muslim liberal, progresif, bahkan moderat mendeskripsikan diri mereka sebagai usclis, atau fundantntalis Tanpa berpikir bahwa ini akan menimbulkan konotasi yang negatif.

${ }^{11} \mathrm{~A}$ bou El-Fadl, SdamatkanIdam 29.

${ }^{12}$ Ibid., 62- 70.

${ }^{13}$ Amin Al-Rihani, TariłaNajduaMulhogatih(Beirut: D ar al-Rihani, 1973), 35-36.

${ }^{14}$ Hubungan antara paham Wahhabi dan kehidupan Badui sangat jelas tergambar di dalam sebuah karya seerti John Lewis Burckhadt, al-Badwwa Wahhabiyzah, penerjemah: Muhammad al-Asyuti, (Beirut: D ar Swidan, 1995; al-Sayyid Muhammad al-Kutdyri>al-SalafiyahbainAhl-al Sumahwaal-Imamiyah (Beirut: al-G hadir li al-Tibasah, 1997), 509.
} 
tidak terikat dengan produk penafsiran yang dihasilkan oleh generasi muslim awal. Sementara Islam formal yaitu kelompok Islam yang selalu memahami teks keagamaan dengan cara absolutisme dan bersifat kaku. Mereka menyeleksi secara ketat segala sesuatu yang datangnya dari pihak luar, serta tetap berpegang teguh pada apa yang disebut dalam teks keagamaan. O leh karena itu mereka akan menolak dengan keras manakala penafsiran itu tidak sepaham dengan penafsirannya.

Adapun Istilah "Timur Tengah" sebagaimana kata Hasan Hanafi, ${ }^{15}$ adalah ungkapan bahasa Inggris (Middle East). Karena, menurut dia, negara-negara Arab adalah "Timur Tengah" jika dibandingkan dengan Cina atau "Timur Jauh", dan negara Arab kawasan Barat (Maghili, Maroko dan sekitarnya), adalah "Timur D ekat" bagi orang Inggris. Sebagaimana Indonesia berada di kawasan Asia Tenggara bagi O rang Barat dan berada di kawasan Barat daya bagi orang Timur. Jadi Istilah Timur Tengah dalam tulisan ini adalah nama untuk kawasan negara-negara Arab (Mesir, Arab Saudi, Iraq, Iran dan sekitarnya).

\section{Peta Pemikiran Fiqih Moderat Timur Tengah dan Relasinya dengan Islam Formalis}

Barangkali tidak ada isu yang paling membedakan antara kelompok moderat dan puritan melebihi topik sifat-dasar dan fungsi hukum, karena hukum memainkan peran sentral di dalam Islam, sampai banyak di kalangan muslim yakin bahwa tanpa hukum agama Islam tidak akan ada. ${ }^{16}$ Oleh karena itu, dalam tulisan ini penulis hanya mengusung isu-isu yang berkaitan dengan persoalan hukum Islam, mengingat hukum Islam menjadi fokus perdebatan yang sangat pelik di samping teologi dari kedua kubu kelompok ini.

Pemikiran hukum/ fiqih dari kedua kelompok ini bila dilihat dari fakta sejarah tidak lain merupakan respon dari perkembangan politik yang berkembang pada saat itu. Di mana kelompok yang berintegrasi dengan dunia Barat (Modern) melahirkan corak fiqih yang lebih moderat, sementara kelompok lainnya yang tetap berupaya untuk mempertahankan tradisi lokal (internal) melahirkan fiqih salaf, yang pada gilirannya dikenal dengan kaum puritan atau salafi.

Jika dibuatkan skema barangkali dapat digambarkan sebagai berikut:

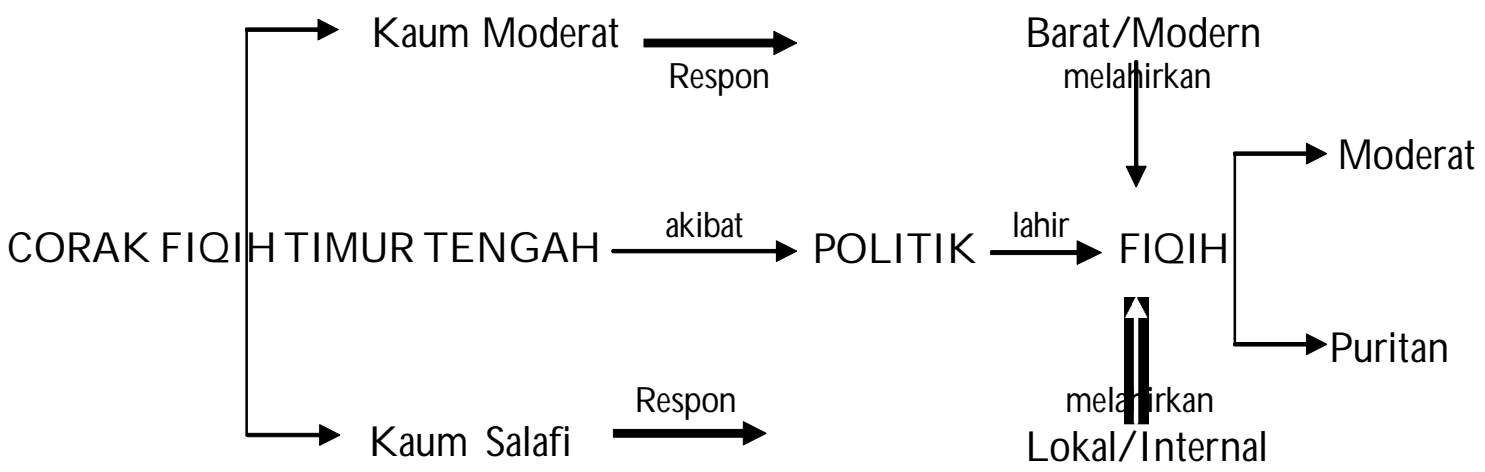

${ }^{15}$ Hasan Hanafi, "Kata Pengantar", dalam IdamGardaDepan: Mosaik PeinkiranIdamTimrTengah M. Ainul Abied Shah (ed.), (Bandung : Mizan, 2001), 21.

${ }^{16}$ Hukum Islam yang dimaksud adalah Sharish dan Fiqih. Karena pada kenyataannya hukum Islam itu terbagi pada dua kategori tersebut. Sharish adalah hukum yang abadi, tetap dan tidak berubah sebagaimana ia berada dalam pikiran Tuhan. Sharish adalah penentuan atau sumber jalan kebenaran dengan subyeknya adalah Tuhan. Sementara Fiqih adalah hukum manusia-ia adalah upaya manusia untuk mencapai dan memenuhi hukum abadi 
D ari gambaran peta tersebut, jelas menunjukkan adanya perbedaan yang sangat menyolok, satu sisi kelompok moderat berupaya merespon nilai moderen, sehingga diharapkan dapat melahirkan fiqih yang lebih dinamis dan fleksibel. Namun di sisi lain, kaum Salafi berupaya mempertahankan tradisi lokal, sehingga corak fiqih yang diusungnya akan lebih kaku dan tidak mau kompromi. Beberapa pemikiran yang diusung oleh kelompok moderat terkait dengan persoalan hukum (fiqih) dan relasinya dengan kaum puritan adalah sebagai berikut:

1. Pemikiran tentang Hukum Pidana ( Fiqih JinayahHridud)

Salah satu pemikiran kelompok moderat dalam kaitan dengan hukum pidana adalah persoalan hudud Kaum moderat berpandangan bahwa kebanyakan peraturan hukum seharusnya ditentukan di tangan rakyat, keculai untuk sekelompok peraturan hukum yang bersifat inti yang dikenal dengan istilah hridud Hridud adalah sehimpunan hukum yang secara eksplisit disebut dalam al-Qur'an. Hukum tersebut meliputi, hukuman bagi kasus zina dan pencurian. Karena hudud mencakup hukuman pidana yang keras, dan aspek pemberlakuan hukuman ini sangat detail dan banyak persyaratan, maka dalam hrudud ini menjadi sulit dalam realitas. O leh karena itu, dalam pandangan kaum moderat model hukuman ini sangat menyulitkan penerapannya, sehingga jarang terimplementasikan.

Sebagai gambaran, kaum moderat mengillustrasikan bahwa untuk membuktikan kasus perzinaan agar sampai pada tingkat penghukuman dengan seratus cambukan, amatlah sulit, karena dibutuhkan empat orang saksi, dan empat orang saksi tersebut harus bisa membuktikan bahwa mereka melihat penis si pelaku sepenuhnya dimasukkan ke dalam vagina. Ini jelas merupakan standar pembuktian yang sangat sulit. Namun apa yang membuat lebih sulit adalah apabila dari beberapa empat saksi tersebut bersaksi bahwa mereka tidak melihat coitus, maka mereka yang mengklaim telah melihat tindakan itu secara penuh dihukum atas tuduhan menfitnah. Jadi, siapapun datang dengan membawa pernyataan tanpa bukti yang tidak dibenarkan oleh yang lain, ia melakukan itu semua dengan resiko. Tentunya, hal ini berfungsi untuk menghindari dari penuduhan yang tidak dibenarkan mengenai seks yang tidak sah. D alam kasus apapun, menurut pendekatan ini, orang bebas tidak menggunakan hukum hrodud Karenaitu, menurut kelompok moderat hukum yang relevan atas kasus ini adalah hukum yang dibuat oleh badan legislatif. ${ }^{17}$

Menurut mereka, sharißat berfungsi sebagai panduan moral dan etika, dan rakyat secara keseluruhan menjadi sumber bagi proses legislasi. Bahkan sebagian kelompok moderat lainnya berpandangan bahwa di dalam demokrasi Islam, badan legislasi seharusnya memasukkan hukum apa pun yang dipandangnya tepat. Namun demikian, harus ada sebuah peradilan tertinggi yang bisa menghapus setiap undang-undang yang tidak sejalan dengan al-Qur'an.

Pandangan kelompok moderat ini nampaknya beralasan, karena dalam kasus hukuman hrodud penerapannya sering membabi buta. Sebagai contoh; Pada tahun 1980

sebagaimana yang ada dalam benak Tuhan. Artinya, fiqih bukanlah kehendak Tuhan itu sendiri, karena ia adalah produk usaha manusia. D engan demikian, fiqih adalah tidak abadi, tidak ajøg sehingga dapat berubah. Lihat Roibin, Sosidog HukumIdam(Malang: UIN Malang Press, 2008), 15 atau bandingkan dengan Abou El-Fadl, SdamatkanIsam, 182.

${ }^{17} \mathrm{Ibid} ., 234-235$. 
terjadi sebuah insiden yang terkenal di Arab Saudi: Para tahanan di penjara Hammam merayakan hari raya Idul Fitri dengan menyanyi-nyanyi. O toritas penjara yang berpaham Wahhabi anti musik berusaha menghentikan mereka dengan memukul. Pangeran Nayef memerintahkan 100 cambukan pada setiap penghuni penjara itu, tanpa pengadilan. $\mathrm{D}$ alam insiden yang lain, anak-anak Shiła umur belasan tahun tersinggung karena keyakinan mereka dihina oleh gurunya, namun Pangeran Meqran dari Madinah justru memerintahkan agar anak-anak itu dicambuk masing-masing 300 kali. ${ }^{18}$ Insiden ini menurut kelompok moderat, jelas melanggar aturan hukum Islam, sebab aturan hukum Islam terhadap hukuman cambuk tidak lebih dari 100 kali cambukan, dan hanya diterapkan untuk tiga kejahatan: zina, pencemaran nama baik, dan minum alkohol. D an penyambukan itu dilakukan dengan tali, kain atau dahan yang kecil, karena tujuannya hanya untuk membuat rasa malu, bukan menyakiti. Penyambukan juga tidak boleh dengan kekuatan penuh; dan bagian yang didera terbatas pada tubuh di atas pinggang. Namun kerajaan Saudi secara rutin menetapkan hukuman cambuk hingga ribuan kali; pada awal tahun 2002 seorang laki-laki di Jeddah dicambuk hinga 4.750 kali kaena berzina dengan iparnya. Alat cambuknya adalah balok kayu atau kabel baja, yang menyebabkan sakit luar biasa. ${ }^{19}$

Pada titik ini, relasi dengan kelompok puritan adalah sama-sama memberikan legitimasi akan hukum hudud Hanya saja, bagi kelompok moderat hukum hudud bisa tidak dilaksanakan sebagaimana ketentuan dalam teks keagamaan, mengingat berbagai kendala yang sangat rumit, sehingga hukum hiduddapat diganti sesuai dengan kesepakatan badan legislasi sebagai lembaga pembuat undang- undang dengan tetap berpedoman pada nilai-nilai al-Q ur'an. Sementara kelompok puritan memandang bahwa ketentuan dalam Teks keagamaan dipandang sebagai ketentuan Tuhan yang tidak dapat diganggu gugat. Bahkan penggantian hukuman hudud dalam bentuk yang lain dipandang sebagai praktik bidah, dan termasuk pengikut inspirasi Barat.

2. Pemikiran tentang Politik dan D emokrasi (Fiqih Sijasi)

Issu yang tidak kalah menariknya di kalangan Islam moderat adalah issu politik dan demokrasi. Munculnya pemikiran tentang fiqih politik ini adalah untuk menolak klaim ekstrim bahwa Islam adalah agama yang lengkap yang mengatur semua urusan termasuk politik, tetapi juga menolak klaim ekstrim kedua yang melihat bahwa Islam tidak ada kaitannya dengan politik. Menurut kaum moderat, kendati Islam tidak menunjukkan preferensinya pada sistem politik tertentu, tetapi dalam Islam terdapat prinsip-prinsip moral atau etika bagi kehidupan bermasyarakat dan bernegara, yang untuk pelaksanaannya umat Islam bebas memilih sistem mana pun yang terbaik. Yang termasuk kelompok ini adalah Muhamad Husein Haikal (lahir 1888), Muhammad Abduh (18621905), Fazlurrahman (lahir 1919), dan Mohamed Arkoun.

Menurut Haikal, di dalam al-Q ur'an dan sunnah tidak terdapat prinsip-prinsip dasar kehidupan yang langsung berhubungan dengan ketatanegaraan. Ayat tentang musyawarah misalnya tidaklah diturunkan dalam kaitan sistem pemerintahan. Al-Qur'an juga tidak secara tegas dan langsung menyebutkan sistem pemerintahan tertentu. Karenanya, tidak

\footnotetext{
${ }^{18}$ Stephen Sulaiman Schwartz, Dua Wajah Isam Modaratismevs Fundamentalisme dalamWacana Gldbal, (Jakarta: Kerjasama Blantika dengan libforal-The Wahid Institut-Center for Islamic Pluralsm, 2007), 378-380.

${ }^{19}$ Ibid.
} 
aneh bila empat khalifah periode Islam awal (al-Khulafa'’al-Rałidun) memang di-bayah masyarakat di masjid, tetapi mereka diangkat tidak selalu melalui pemilihan. ${ }^{20}$

Nabi sendiri bahkan membiarkan sistem pemerintahan Arab asalkan menerima baik agama yang dibawanya. D alam perkembangan selanjutnya juga pengaruh luar (Bizantium dan Persia) terhadap pemerintahan Islam makin mendalam dan tampak. Namun demikian, sejauh yang bisa kita baca dari sumber-sumber Islam, paling tidak ada 3 prinsip dasar peradaban manusia termasuk dalam ranah politik. Petama, prinsip monoteisme murni. Keedua, prinsip sunnah (hukum) Allah yang tidak pernah berubah, dan keiga, prinsip persamaan antar manusia sebagai konsekuensi prinsip pertama dan kedua. Realisasi prinsip-prinsip itu diwarnai oleh semangat persaudaraan, cinta kasih, rasa keadilan, dan takwa. ${ }^{21}$

Muhammad Abduh, meskipun hidup jauh sebelum Haikal dan guru dari Rashid Rid maupun Raziq, tampaknya masuk kategori ketiga. Hal ini karena menurutnya Islam bukanlah agama semata-mata, melainkan mempunyai hukum-hukum yang mengatur hubungan antar sesama Muslim dan sesama manusia lainnya yang untuk memberlakukannya dibutuhkan penguasa atau negara. Dalam bahasa lain, bagi Abduh, kaitannya dengan agama adalah subsider saja dan dalam pendapatnya juga bahwa tidak ada orang atau lembaga yang memegang kekuasaan keagamaan dengan mempunyai kewenangan wakil Tuhan di muka bumi. Baginya, kepala negara merupakan seorang sipil yang diangkat dan dapat diberhentikan rakyat, dan kepada mereka dia bertanggung jawab. Seiring dengan pengakuannya akan konsep demokrasi, Program Partai Nasional Mesir yang dirumuskannya sendiri pun membuka keanggotaan kepada seluruh rakyat Mesir, yang beragama Islam, Yahudi, Kristen atau lainnya. ${ }^{22}$

Bila Haikal tidak menyebut preferensi Islam pada sistem politik tertentu, maka pemikir Islam setelahnya, yaitu Fazlur-Rahman, Mohamed Arkoun menyebut bahwa dari prinsip-prinsip yang disebut al-Q ur'an dan $\mathrm{H}$ ddith, , preferensi Islam adalah sistem politik demokratis. D alam berbagai tulisannya Fazlur-Rahman menekankan masyarakat Islam adalah masyarakat menengah yang tidak terjebak pada ekstrimitas, dan ulisal-amrnya (para pemegang kekuasaan) adalah mereka yang tidak menerima konsep elitisisme ekstrim. Masyarakat Islam adalah masyarakat yang egaliter dan terbuka atau inklusif, saling berbuat baik dan kerjasama, dan tidak melakukan diskriminasi berdasarkan gender atau kulit. Selanjutnya Fazlur-Rahman menjelaskan kosep shurałmusyawarah). Shurabukan berarti bahwa seseorang meminta nasehat kepada orang lain, seperti yang terjadi dahulu antara khalifah dan ahl holl wa al-'aqd, tetapi nasehat timbal balik melalui diskusi bersama. Tentu saja konsep demokrasi yang dipilih Fazlur-Rahman ini dengan, katanya lebih lanjut, berorientasi pada etika dan nilai spiritual Islam, tidak semata-mata bersifat material seperti di Barat. ${ }^{23}$ Karena pilihannya pada sistem demokrasi itulah, ia mengkritik para tokoh Islam yang menentang demokrasi, seperti al-Maududi.

\footnotetext{
${ }^{20}$ Muhammad Husein Haikal, PemeintahanIdam(Jakarta: Pustaka Firdaus, 1993), 47.

${ }^{21}$ Ibid., 78-81. atau bandingkan dengan Muhamad Azhar, Filsafat Pditik: Pebandingan antara Isamdan Barat (Jakarta: Rajawali Pers, 1996), 68.

${ }^{22}$ Munawir Sadzali, Idamdan TataNeegra(Jakarta: UI Press, 1993), 84.

${ }^{23}$ Muhamad Azhar, Filsafat Pditik: PebbandinganantaraIsamdan Barat(Jakarta: Rajawali Pers, 1996), 43.
} 
Sebagaimana Fazlur-Rahman, Arkoun juga berpendapat sama. Pertama-tama ia menjelaskan perbedaan antara kekuasan dan wewenang. Wewenang menurutnya bersifat mistis-teologis seperti ketika Nabi di Mekah dan kekuasan bersifat rasional seperti ketika Nabi di Madinah yang selalu dikelilingi dewan yang beranggotakan paling tidak 10 orang. Selanjutnya, Arkoun menerima pernyataan Ibn Khaldun bahwa sistem kekhalifahan tidak berbeda dengan sistem kerajaan yang dominatif dan hegemonik yang telah melakukan tindakan sakralisasi terhadap yang duniawi seperti terlihat pada terminologi bayah dan wakil Allah di muka bumi. Dari sini kemudian ia lebih menyetujui negara demokratis, mengkritik para ulama yang telah ikut melestarikan status quo kekuasaan dinasti yang jauh dari moral Islam, dan mengecam pelaksanaan konsep dhimmłyang terlindung) bagi masyarakat non Muslim. D alam pandangannya, kendati penerapan konsep itu lebih baik dibanding dengan kaum Muslimin yang hidup di tengah mayoritas umat agama lain, tetapi tidak dapat dipungkiri bahwa model toleransi dhimi «ersebut adalah model toleransi tanpa peduli. Ini karena ia biasanya disertai dengan tindakan mengurangi peran kelompok lain yang non Muslim. Sebagai pemikir modern, Arkoun di satu sisi mengkritik habis sekularisasi gaya Ataturk di Turki yang bagi Arkoun merupakan bentuk kesadaran naif yang didasari oleh kekagetan budaya, tetapi di pihak lain ia juga menolak pembentukan negara Islam ala Khomeini di Iran, karena telah melakukan sakralisasi terhadap sesuatu yang sebenarnya duniawi. Adapun prinsip kenegaraan dalam Islam adalah shura,ïjihad dan penerapan shari'gh yang tujuannya, bagi Arkoun, untuk mewujudkan masyarakat yang bermoral, bertanggung jawab, dan bermartabat, sehingga anggota masyarakat Muslim diridģi Allah dalam menjalankan tugas pribadi dan sosialnya secara harmonis. ${ }^{24}$

Meski pandangan kaum moderat tentang demokrasi ini dinilai oleh sebagian kelompok memiliki kekurangan, tetapi diakui atau tidak demokrasi sebagai sesuatu yang tidak ternilai harganya, sampai sekarang belum ditemukan alternatif yang lebih unggul. D emokrasi, baginya adalah majority nuleminarity night, yaitu sistem politik dengan prinsip mayoritas dengan tidak mengganggu kepentingan minoritas yang paling fundamental.

Bahkan di era kontemporer saat ini, issu tentang D emokrasi manjadi issu yang tetap menarik. D alam buku terbarunya, MakingIdamDemoratic Social Movements and the Post-Isamist Tum sebagaimana dikutip oleh Q urtubi, A sef Bayat memberi ulasan menarik mengenai fenomena ini. Dia mengatakan bahwa diskusi tentang "Islam sesuai atau tidak sesuai dengan demokrasi" sudah tidak relevan lagi, karena dunia Islam, khususnya Arab dan Timur Tengah, sedang in the process of demorag. Kesimpulan Bayat ini didasarkan pada hasil risetnya tentang "post-Islamist" di Iran dan Hizb al-Wasat/(Partai Tengah/ Moderat) di Mesir, di mana menurutnya, gerakan-gerakan sosial dan perjuangan politik yang dipelopori organisasi mahasiswa, kaum perempuan, akademisi, aktivis, dan bahkan kaum ulama, telah memberi kontribusi positif bagi perkembangan demokrasi, pluralisme, dan liberalisme, serta mendorong pertumbuhan divil soidydi kedua negara itu. Iran memang dikenal dunia internasional sebagai negara yang telah melahirkan tokoh-tokoh yang bersuara lantang tentang demokrasi dan kebebasan sipil, terutama sejak Imam K homeini memberlakukan otoritas dan supremasi ulama di atas segela-galanya dan memberangus

\footnotetext{
${ }^{24} \underline{\mathrm{http}: / / \text { bmulyana.multiply.com/journal/ item/4/ Pemikiran Politik di Timur Tengah. }}$
} 
ekspresi avil libeties Suara lantang itu tidak hanya muncul dari kelompok aktivis NGO dan kaum intelektual kampus saja, tetapi juga dari dalam millah sendiri yang selama ini dikenal konservaif. ${ }^{25}$

Di Mesir, perubahan fundamental juga terjadi di tubuh Hłzbal-Wasat/sayap pecahan

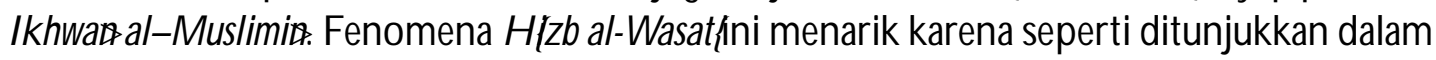
studi Bayat dan juga Anthony Shadid dalam Legay of thePropht: Despots, Demorats, and the NewPditics of Isam kelompok/ partai "Islam kanan" ini telah melakukan reformasi mendasar mengenai fondasi keagamaan kepartaian, berupa, antara lain; menerima nonMuslim (khususnya Kristen Koptik) dan kaum perempuan dalam struktur politik partai dan calon legislatif, serta bersedia bekerja sama dengan partai non-Islam. Pemandangan ini tentu tidak umum buat partai Islam kanan yang selama ini dikenal memiliki visi

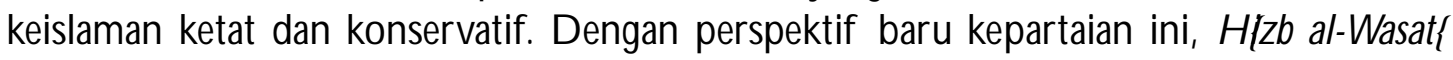
menegaskan keberbedaannya dengan mainstream Ikhman al-Mudimin(IM) di Mesir yang dikenal konservatif dan tidak menghargai kebebasan sipil, anti-demokrasi dan pluralisme. ${ }^{26}$

Penegasan keberbedaan ini disampaikan oleh salah satu pendiri Hïzb al-Wasat/ Essam Sultan, yang mengatakan bahwa partainya berbeda secara fundamental dengan IM dalam hal "keimanan" pada pluralisme, demokrasi, kebebasan berpikir dan berekspresi, serta hal-hal yang berkaitan dengan isu-isu kontemporer. Essam Sultan mengklaim bahwa IM, dengan pandangan-pandangan konservatifnya, telah mengisolasi diri dari komunitas luar non-IM, padahal menurutnya kelompok/ grup di luar partai harus dijadikan sebagai bagian dari perubahan global. Renaissancebagi masa depan Mesir, menurutnya, tidak akan berhasil tanpa melibatkan komunitas yang lebih luas termasuk non-Muslim dan kaum perempuan yang selama ini selalu dalam "pojok" sejarah kepolitikan Islam. ${ }^{27} \mathrm{D}$ emikianlah issu demokrasi yang diusung oleh Islam moderat akhir-akhir ini di wilayah Timur Tengah.

Gambaran demokrasi yang diusung oleh kaum moderat, jelas menunjukkan akan keterbukaan dalam sistem pemerintahan, siapapun bisa masuk di dalamnya, tanpa ada sekat agama dan kelompok, termasuk issu gende. Bahkan untuk memerintah suatu Negara, kehendak rakyat mempresentasikan kedaulatan politik. Karena itu pandangan atau suara setiap warga, muslim atau yang lain, seharusnya juga dipertimbangkan dalam rangka mendapatkan kehendak mayoritas, sehingga hasilnya nanti dapat menggambrkan kehendak rakyat. Oleh karena itu, kehendak mayoritas rakyat harus dihormati dan tetap dalam bingkai parameter konstitusional; jika melanggar batas-batas konstitusional, kehendak mayoritas rakyat tidak akan dihormati.

D alam hubungannya dengan Islam puritan, issu ini menjadi menarik karena kaum puritan dengan serta-merta menolak adanya issu demokrasi dalam suatu pemerintahan, karena demokrasi dipandang sebagai produk dunia Barat. Kaum puritan sangat bersikukuh untuk menciptakan kembali lembaga khilafahsebagai landasan sistem pemerintahan Islam. D engan ini, mereka membayangkan model yang dibangun oleh empat Khulafá'rl-Rashidum yang memegang kekuasaan penuh sepeninggal Nabi saw.

${ }^{25}$ Lihat Sumanto al-Q urtuby, "Fundamentalis Moderat di TimurTengah" dalam Artikd http:/ / www.islamlib.com. Diaksestanggal $27 \mathrm{Mè} 2010$.

${ }^{26}$ Ibid.

${ }^{27}$ Anthony Shadid , Legay of theProphe: Despots, Demorats, and theNewPditics of Idam( 2002: 262). 


\section{Pemikiran tentang Konsep Jihad (Fiqih Jihad)}

Aspek penting yang menjadi sorotan bagi kaum moderat adalah masalah "jihad". Jihad adalah prinsip utama dalam aqidah Islam. Istilah itu sendiri secara harfiyah berarti "berusaha keras, tekun bekerja, berjuang, mempertahankan." Berdasar pengertian ini kaum moderat berpandangan bahwa dalam banyak hal jihad berarti etika kerja yang kuat secara spiritual dan material di dalam Islam. Kesalehan, pengetahuan, kesehatan, keindahan, kebenaran, dan keadilan tidaklah dimungkinkan tanpa jihad-yaitu tanpa kerja keras dan berkesinambungan secara tekun. Oleh karena itu, membersihkan diri dari kesombongan dan kerendahan, menuntut ilmu, menyembuhkan orang sakit, memberikan makan kepada kaum yang kekurangan, menegakkan kebenaran dan keadilan, bahkan dengan resiko pribadi yang besar, semuanya adalah bentuk jihad. ${ }^{28}$

Menurut kelompok moderat, al-Qur'an menggunakan istilah jihad kebanyakan untuk merujuk pada tindak kerja keras guna mewujudkan tindakan Tuhan di muka bumi ini, yang mencakup semua aktifitas seperti dijelaskan di atas. ${ }^{29} \mathrm{Nabi}$ Muhammad berulangulang mengajarkan bahwa bentuk jihad terbesar adalah memerangi hasrat rendah manusia atau menyampaikan kebenaran di hadapan kekuasaan yang menindas. Kelompok moderat juga berpandangan bahwa berusaha sekuat tenaga dan bekerja keras dalam perang, asalkan perang tersebut adil dan baik, juga termasuk dalam katagori jihad.

Jihad menjadi simbol kuat bagi kesungguhan, kerja keras, dan kesuksesan di dalam sejarah Islam. Sebagai simbol, jihad dipakai untuk menghimpun antusiasme dan gairah untuk beragam tujuan, termasuk perang. D alam perang, jika pertempurannya adalah antara muslim dan nonmuslim, maka penguasa menjadi seseorang yang menyerukan jihad. Akan tetapi jika tujuannya adalah perkara internal, seperti protes masyarakat, pemberontakan, penggalangan dana untuk membangun tempat pendidikan, atau menghimpun dana untuk mendirikan perpustakan atau cagar alam bagi anjing-anjing dan kucing jalanan (yang biasa menjadi praktik umum di era klasik), seruan jihad biasanya dikeluarkan oleh sarjana yang berpengaruh yang telah terbukti menguasai suatu perkara tertentu. ${ }^{30}$

Kelompok moderat juga berpendapat bahwa al-Q ur'an tidak menggunakan kata jihad untuk merujuk pada perang atau pertempuran. Perang atau pertempuran dirujuk dengan kata qital. Sementara al-Q ur'an menyebut jihad sebagai mutlak dan tak terbatas. Jihad pada dasarnya baik, sementara qitaltidak demikian. Jihad itu baik karena kerja keras menuju tujuan yang baik. A kan tetapi qital (perang) adalah sesuatu yang berbeda sama sekali. Qital dalam al-Qur'an dibatasi oleh kondisi tertentu, sedangkan desakan akan jihad, seperti acuan pada keadilan dan kebenaran, mutlak dan tak bersyarat. Pada setiap kesempatan terpisah ketika al-Qur'an mendesak umat Islam untuk berperang, segera mensyaratkan tuntutan itu dengan sebuah perintah kepada kaum muslimin untuk tidak melampaui batas, untuk memaafkan, dan mencapai perdamaian. ${ }^{31}$ Walaupun fakta ini dapat diketahui dengan sekedar membaca teks al-Q ur'an, anehnya realitas tekstual ini

\footnotetext{
${ }^{28}$ Lihat Abou El-Fadl, SdamatkanIdam 264-265.

${ }^{29}$ Lihat al-Q ur'an 9 (al-Tawbah): 19; 29: 6; 2 (al-Baqarah): 218; 8 (al-Anfab): 72, 74, 75; 9 (al-Tawbah): 20 dan 88; 49 (al-Hujurat): 15; 16 (al-Nahl): 110. dan masih banyak lagi di dalam al-Q ur'an.

${ }^{30}$ Abou El-Fadl, SdamatkanIsam 266-267.

${ }^{31}$ Lihat al-Q ur' an 5 (al-Maidah): 8, 2 (al-Baqarah): 190; 5 (al-Maidah): 87; 7 (al-A'raf): 55.
} 
cenderung dilupakan oleh banyak sarjana muslim dan nonmuslim yang mempelajari alQur'an. Meski demikian, tidak diperselisihkan bahwa al-Qur'an tidak penah mendukung pilihan militer tanpa mensyaratkan pilihan itu dengan beberapa cara yang signifikan.

Perdebatan tentangjihad oleh dua kelo mpok ini memang tidak akan pernah berakhir, karena adanya perbedaan mendasar dan fundamnetal dalam membaca teks al-Q ur'an tentang perang. Bagi kelompok puritan seperti Maududi, Sayyid Q uthb, dan yang lebih baru Bin Laden serta para pendukung bom-bom teroris di Israel, mengambil inspirasi dari sebuah ayat al-Q ur'an yang mengatakan: "Telah diizinkan mengangkat senjata kepada mereka yang diserang, karena mereka telah diperlakukan dengan buruk" ${ }^{32}$ Ayat ini dikutip untuk membenarkan peperangan dan gerilya melawan Amerika dan Israel dengan alasan bahwa keduanya adalah penyerang Islam, bukan sekedar musuh pemimpin Islam atau para perebut wilayah. ${ }^{33}$

Sekalipun tidak dapat ditampik bahwa kelompok moderat juga mengakui adanya jihad dalam bentuk peperangan, tetapi menurut mereka al-Q ur' an selalu menekankan bahwa Allah tidak menyukai agresi dan tidak mencintai para agresor. Al-Qur'an mengingatkan umat Islam agar mereka harus secara kritis merenungkan cara mereka berhubungan dengan orang lain agar mereka jangan sampai tanpa sadar terjatuh pada sikap-sikap yang tidak adil. ${ }^{34}$ Memang al-Q ur'an mengakui hukuman bagi mereka yang berbuat salah, dan mengakui bahwa kadang kala diperlukan bertindak dengan gaya menghukum. Jika diserang umat Islam bisa membela dirinya dengan cara yang baik, namun bila musuh berhenti, umat Islam harus bisa menahan diri dari tindakan melakukan kejahatan. Dalam konteks ini al-Qur'an menyatakan: "Jika mereka menyerangmu, seranglah mereka seimbang dengan serangannya terhadapmu (bunuhlah), jika mereka berhenti, maka tidak ada permusuhan lagi, kecuali bagi orang-orang yang zalim" ${ }^{35}$ Konteks ayat ini, al-Q ur'an sedang menunjuk pada perang dalam rangka membela diri, khususnya merujuk pada situasi ketika umat Islam dalam keadaan terpaksa. D ari sini jelas bahwa kekerasan bukanlah situasi yang ideal. Al-Qur'an berbicara tentang situasi ketika umat Islam harus terpaksa mengunakan kekerasan karena sudah tidak ada pilihan lain.

D alam menyikapi persoalan jihad ini, seorang ulama' besar yang sekaligus sebagai ilmuwan tersohor di dunia saat ini, yaitu Yusuf Q ardawi memberikan pandangannya terhadap jihad tersebut dengan ungkapan yang sangat moderat. ${ }^{36}$ Mengenai kategri petama, beliau mengatakan, ini adalah sebuah kategori yang berusaha untuk memberikan selubung kelalaian terhadap jihad dan menjauhkan jihad dari kehidupan ummat. Mereka, malahan, menganggapnya sebagai kepedulian dan peran utama mereka meningkatkan nilai-nilai spiritual dan amal-amal kebajikan ummat sebagaimana klaim mereka, dan mempertimbangkan hal ini sebagai jihad yang utama: perjuangan terus-menerus melawan setan dan hawa nafsu seseorang.

Kategri kedua, beliau mengatakan, Sebagai lawan dari kategori di atas, di sana ada

${ }^{32}$ Lihat al-Qur'an 22 (al-Hajj): 39.

${ }^{33}$ Stephen Sulaiman Schwartz, DuaWajahIdam 202.

${ }^{34}$ Lihat al-Q ur'an 2 (al-Baqarah): 190; 5 (al-Maidlah): 87; 7 (al-A 'raf): 55.

${ }^{35}$ Lihat al-Q ur'an 2 (al-Baqarah): 192-194.

${ }^{36}$ Lihat Rajab Abu Malih "Resensi fiqh of Jihad” Y usuf Q ardlawi dalam CitusDakwatuma, diakses tanggal 20 Mei 2010. 
yang lain lagi yang mempersepsikan jihad sebagai sebuah "perjuangan melawan seluruh dunia". Mereka tidak membedakan antara yang memerangi kaum muslimin, berdiri di jalan dakwah, atau yang mencoba menjauhkan mereka dari agamanya, dan mereka yang melebarkan jembatan perdamaian kepada kaum muslimin dan menawarkan rekonsiliasi serta pemulihan hubungan dengan mereka, tidak menggunakan pedang kepada mereka dan tidak mendukung musuh dalam melawan mereka. Menurut kategori ini, semua orang kafir adalah sama. Orang-orang yang tergolong kategori ini percaya bahwa ketika kaum muslimin memiliki kemampuan, mereka berkewajiban untuk memerangi orang-orang kafir hanya dengan pertimbangan kekafiran mereka, yang mereka anggap sebagai alasan yang memadai untuk memerangi orang-orang kafir tersebut.

Beliau lalu memilih pendekatan moderat yang direpresentasikan oleh kategori ketiga, beliau mengatakan, kategri ketiga adalah "ummat yang moderat" (ummat pertengahan) di mana Allah swt telah memberi petunjuk kepada pendekatan moderat dan diberikan pengetahuan, kebijaksanaan, dan pemahaman yang dalam mengenai shari sh dan realitas. Oleh karenanya, kategori ini tidak tergelincir kepada kelalaian dari kategori pertama yang berusaha untuk membiarkan hak ummat tanpa dipersenjatai dengan kekuatan, alQur'an-nya tidak dijaga dengan pedang, serta rumah dan tempat-tempat sucinya tanpa penjaga untuk melindungi dan mempertahankan mereka.

D emikian juga, kategori ini tidak jatuh pada tindakan berlebihan dan ekstrimisme dari kategori kedua yang berusaha untuk memerangi orang-orang yang damai, dan mendeklarasikan perang melawan semua orang tanpa membeda-bedakan; putih atau hitam, di Timur atau di Barat. Tujuan mereka melakukan hal itu adalah untuk mengarahkan orang-orang ke (jalan) Allah swt, mengantarkan mereka yang terbelenggu ke Surga dan membawa mereka secara paksa dengan tangan ke jalan yang lurus. Mereka (kategori kedua itu) lebih lanjut menambahkan bahwa tujuan mereka adalah untuk menghilangkan hambatan-hambatan di depan orang-orang itu yang dibentuk oleh rezim yang złlim yang tidak memungkinkan mereka untuk menyampaikan firman Allah dan seruan Rasul-Nya kepada masyarakat, sehingga mereka dapat mendengar dengan keras dan jelas dan bebas dari segala noda.

\section{Penutup}

D emikianlah gambaran singkat pemikiran Islam moderat Timur Tengah yang dapat penulis paparkan, sekalipun hanya sebatas pemetaan pemikiran yang sangat sederhana, tetapi setidaknya dari gambaran di atas, dapat diketahui bahwa pemikiran Islam moderat mulai diminati di kawasan ini. Yang jelas munculnya pemikiran Islam moderat Timur Tengah merupakan varian yang tidak lepas dari trend atau kecenderungan pemikiran Islam yang ada di Timur Tengah, yaitu pemikiran yang konservatif-tradisionalis. D engan adanya trend pemikiran moderat Timur Tengah saat ini merupakan gambaran bahwa kekerasan maupun tindakan konservatif sudah mulai tidak diminati dan bahkan ditingalkan karena tindakan itu tidak membawa kedamaian dan tidak selaras dengan misi rahthah li al-alımin

Pada dasarnya, setiap trend pemikiran tersebut, jika dikaji lagi secara mendalam, akan muncul varian-varian lain yang lebih komplek. Akan tetapi, kesemuanya berperan dalam menentukan harapan dan obsesi bangsa kawasan Timur Tengah di masa mendatang. Ketiga 
issu yang diusung tersebut, secara kasar, bisa dilihat dalam perspektif paradigmatis, di mana kelompok moderat mempunyai bahasa khusus yang berbeda, yang tidak dipahami oleh kelompok puritan. Kalaupun bisa dikomunikasikan, dialog antara mereka sulit untuk saling dipertemukan, karena masing-masing dari mereka menganggap yang paling compatadedengan kondisi dunia Islam Timur Tengah, sebenarnya mereka telah terperangkap ke dalam kerangka epistemik yang pada akhirnya mengarah pada dogmatisme (untuk menghindari istilah sektarianisme).

Tipologi pemikiran moderat seperti yang diilustrasikan di atas adalah refleksi dari interaksi dan sikap para intelektual Timur Tengah terhadap isu di sekitar tradisi dan modernitas. Sikap tersebut kemudian memunculkan - di samping discarsebaru menyangkut isu tradisi dan modernitas - idiom-idiom dan istilah baru dalam kamus pemikiran fiqih Arab yang sebelumnya kurang diminati dan kurang menjadi perhatian, menjadi menarik untuk terus dikaji oleh dunia Islam lainnya, terutama di negara-negara muslim di belahan dunia ini, khususnya di Indonesia, sehingga Islam moderat tidak hanya sebagai simbol klasik yang tertuang dalam teks keagamaan, tetapi pada akhirnya menjadi realitas empirik dalam tatanan kehidupan masyarakat muslim dalam bingkai fiqih yang selalu membawa rahmat, baik di

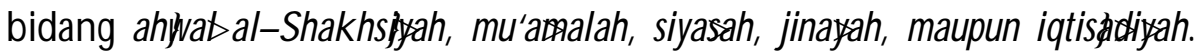

\section{Daftar Rujukan}

Malih, Abu Rajab. "Resensi Fiqh of Jihad" Yusuf Q ardawi dalam Citus Dakwatuma, diakses tanggal 20 Mei 2010

Azhar, Muhamad. Filsafat Pditik: Pejbandingan antara Isamdan Barat. Jakarta: Rajawali Press, 1996.

Kutdyri>(al), al-Sayyid Muhammad. al-Salafiyah bayn Ahl al-Sumah wa al-Imaniyzah Beirut: al-Ghadir li al-Tibałah, 1997.

Al-Q urtuby, Sumanto. "Fundamentalis Moderat di Timur Tengah" dalam Artikd http:// www.islamlib.com. Diakses tanggel $27 \mathrm{Me} 2010$.

Rihani (al), Amn, Tarilkh Najd wa Mulhaqatih Beirut: D ar al-Rihani, 1973.

Burchhadt, John Lewis. Al-Bawwa Wahhabiyah, Penerjemah: Muhammad Al-Asyuti, Beirut: Dar Swidan, 1995.

D epartemen Agama R. I. Al-Quran dan Tejemahnja. Semarang: CV. al-Syifa', 2006.

El-Fadl, Kholed Abou. Sdamatkan Idamdan MudimPunitan Jakarta: Serambi Ilmu Semesta, 2006

Hanafi, Hasan. "Kata Pengantar", dalam Idam Garda Depan: Mosaik Penikiran IstamTimr Tengah M. Ainul Abied Shah (ed.). Bandung : Mizan, 2001. . Isamog 2 dari Rasionalisme e Empinisme Yogyakarta: LkiS, 1973.

Haikal, Muhammad Husein. Pemikiran Idam Jakarta: Pustaka Firdaus, 1993.

http:// tabloiddiplomasi.com/ index.php/ previous-isuue/ 52-maret-2008/ 474-islammoderat-dalam-peta-diplomasi-global, Edisi: Maret 2008.

Nasution, Harun. Filsafat dan Mistiasme Jakarta: Bulan Bintang, 1973.

Roibin. Sosidog HukumIsam Malang: UIN Malang Press, 2008.

Sadzalai, Munawir. Isam dan Tata Negara. Jakarta: UI Press, 1993.

Schwartz, Stepehen Sulaiman. Dua Wajah Isam Modkatisme vs Fundametalisme alam Wacana 
118 Pemikiran Fiqih Moderat di TimurTengah dan Relasinya dengan Gerakan Fiqih Formalis

Gldbal. Jakarta: Kerjasama Blantika denan Libforal-The Wahid Institut-Center of Islamic Pluralism, 2007.

Shadid, Anthony. Leagy of thePropht: Despots, Demorats and theNewPditics of Istam 2002. Wati, Ana Bilqis Fajar. "Pemikiran Keagamaan Fazlur Rahman (Studi atas Sumber-sumber Hukum Islam dan Terbukannya Pintu Ijtihad" dalam Antdog Kajian Isam Seri 10, Surabaya: PPS IAIN Sunan Ampel Press, 2006. 